Volume 9 - 2019 |n. 1

\title{
Educação na Bolsa de Valores: o FIES e o ensino
}

\section{superior privado}

\author{
Maíra Teixeira Silva \\ Faculdade UBS, São Paulo/SP - Brasil \\ Felipe Furini Soares \\ Universidade Federal da Paraíba (UFPB), João Pessoa/PB - Brasil
}

\section{Resumo}

O artigo trata das políticas de transferências de recursos públicos do ensino superior para agentes privados. Parte-se do histórico de processos privatizantes do ensino superior no Brasil, realizando-se uma análise do Fundo de Financiamento Estudantil (FIES), principalmente em virtude de seu crescimento superior a $2000 \%$ no período entre 2010 e 2016. Busca-se dimensionar os impactos dessa política no que se refere ao capital privado e financeiro, aos efeitos concorrenciais, além das questões oriundas da falta de uma fiscalização dos resultados. Dentro do percurso metodológico foi realizada revisão bibliográfica, análise de material jornalístico e entrevistas semiestruturadas com especialista e estudiosa sobre o tema. Analisaram-se ainda relatórios quantitativos de consultoria e do Conselho Administrativo de Defesa Econômica (CADE), além de requerimentos de dados a órgãos federais via Lei de Acesso à Informação (LAl). Verificou-se que a aposta pela ampliação do acesso ao ensino superior ancorou-se na oferta de agentes privados, por intermédio do endividamento da população, promoção de baixa qualidade e aglutinação de grupos privados.

Palavras-chave: Instituições de Ensino Superior (IES). FIES. Bolsa de Valores.

\section{Education and the Stock Exchange: FIES and private higher education}

\begin{abstract}
The article approaches transfer policies of public resources to private agents in higher education. Based on the history of privatization processes in higher education in Brazil, the Student Financing Program (FIES) was analyzed, mainly due to its growth of over $2000 \%$ between 2010 and 2016. It is sought to measure impacts of this policy regarding private and financial capital, competitive effects, and issues arising from the lack of results monitoring. As a methodological course, bibliographical review, analysis of journalistic material and semistructured interviews with a specialist and researcher on the subject were carried out. It was also analyzed quantitative consulting reports and the Administrative Council for Economic Defense (CADE), in addition to requesting data from federal agencies via the Information Access Act (LAI). It was verified that the commitment to increase access to higher education was anchored in the offer by private agents, through the indebtedness of the population, promotion of low quality and agglutination of private groups.
\end{abstract}

Keywords: Higher Education Institutions. FIES. Stock Market. 
Educação na Bolsa de Valores

\section{Introdução}

Este artigo surge da inquietação relativa ao crescimento de mais de $2000 \%$ de recursos disponibilizados pelo Fundo de Financiamento Estudantil (FIES), ocorrido entre 2010 e 2016, trazendo a reboque uma expansão de grandes grupos de ensino superior privado. Essa política pública de financiamento de graduação, ao mesmo tempo que amplia o acesso de estudantes ao ensino superior, configura uma aposta no financiamento da oferta por agentes privados.

Tal direcionamento evidencia um enfraquecimento do ensino público superior ${ }^{1}$, a partir da substituição da educação como um direito, para um serviço que se adquire no mercado. De acordo com Hill (2003), essa é uma ofensiva global, que age na redução do gasto público e na liberação para que agentes privados possam operar no mercado a partir da comercialização de serviços educacionais.

Dessa forma, o artigo buscará apurar reflexos da política pública do FIES voltados para a educação superior privada, que privilegiam o capital privado e o financeiro, sem uma efetiva fiscalização dos resultados do ponto de vista da qualidade educacional. Buscará ainda descrever os efeitos concorrenciais nocivos oriundos da política pública mal acompanhada e mal fiscalizada, um dos fatores que resulta na concentração do setor, segundo o Conselho Administrativo de Defesa Econômica (CADE) ${ }^{2}$ e pesquisas acadêmicas (CARVALHO, 2013; MARQUES, 2013; SAMPAIO, 2014).

Como percurso metodológico, foi realizado uma primeira fase de revisão bibliográfica, sendo acompanhada de pesquisa documental de relatórios técnicos, além de demonstrações financeiras dos agentes privados, que permitissem dimensionar o impacto dos recursos advindos do FIES na estrutura financeira dos agentes, bem como oscilações no valor de mercado de tais instituições.

Nesse sentido, foram analisados os recursos públicos como um atrativo ao mercado financeiro, a partir dos fundos de private equity ${ }^{3}$ (nacionais e internacionais) e das empresas de ensino superior listadas na BM\&FBovespa (hoje renomeada de B3). Finalmente, foram realizadas entrevistas estruturadas, no sentido de entender a visão de especialistas no tema. Para a entrevista, selecionou-se um representante de mercado financeiro, dedicado ao setor educacional privado, e uma pesquisadora na área de mercantilização e internacionalização do ensino superior. Essa escolha teve por objetivo contrapor posições sobre o reflexo do FIES na oferta educacional a partir de empresas privadas.

1 Expandir a oferta educativa por agentes privados traz fortes impactos para a pesquisa, haja vista que todas as 20 universidades destacadas em produção de pesquisa, na pós-graduação no Brasil, são públicas, conforme pesquisa realizada para a Coordenação de Aperfeiçoamento de Pessoal de Nível Superior (Capes) (2017). Pesquisa no Brasil: Um relatório produzido pela Clarivate Analytcs para Capes, a partir de análise de dados de pesquisa entre os anos de 2011 e 2016. Relatório disponível em: <http://www.capes.gov.br/ images/stories/download/diversos/17012018-CAPES-InCitesReport-Final.pdf>.

2 O Conselho Administrativo de Defesa Econômica (Cade) é uma autarquia federal, que exerce atribuições previstas pela Lei $n^{\circ} 12.529 / 2011$. Tem como missão zelar pela livre concorrência no mercado, sendo a instituição do Poder Executivo responsável pela investigação e decisão sobre questões concorrenciais, além de fomentar e disseminar a cultura da livre concorrência.

3 Diz respeito a fundos de investimento que detêm participação em empresas de capital aberto ou fechado, com participação do investidor nos foros de gestão da entidade investida. Para maior aprofundamento, consultar: Associação Brasileira de Private Equity e Venture Capital (ABVCAP): <http://www.abvcap.com.br>. 
Antes de avançar é importante retomar a relação entre a ação governamental e aos agentes privados na educação superior brasileira. De acordo com Cunha e Góes (2002), durante o Golpe Civil-Militar de 1964, a partir da revisão em 1965 do Plano Nacional de Educação, destinou-se 5\% dos recursos do Fundo Nacional do Ensino Superior para a concessão de bolsas de estudos em universidades particulares. As matrículas no ensino superior público correspondiam a $75 \%$ em 1964. Já em 1984, a participação foi reduzida para $25 \%$, dada a elevada abertura de instituições privadas de ensino superior.

Mesmo com toda a bonança de abertura de vagas, incentivada pelos subsídios governamentais, a crise do "milagre econômico brasileiro" fazia pressão sobre os alunos do ensino privado. Dessa forma, empresários do setor universitário realizaram lobby para salvar seus negócios. A solução encontrada foi a concessão de crédito educativo, a partir de duas modalidades: uma para pagamento de mensalidades e outra para manutenção estudantil do alunado. Conforme Cunha e Góes (2002) explicam, o setor privado da educação ganhava pelos bancos, já que podiam fazer empréstimos com recursos oriundos do Banco Central brasileiro. Para as universidades privadas houve a redução do risco de inadimplência, haja vista que o governo era um pagador que oferecia mais garantias que o alunado. Consequentemente, com o aumento da crise, a bomba do endividamento estourou nas mãos dos alunos; em 1983, dos 250 mil alunos tomadores de crédito, 200 mil eram inadimplentes (CUNHA; GÓES, 2002).

Pinto (2002) ressalta as movimentações e alterações que permitiram a aprovação da Lei de Diretrizes e Bases da Educação (LDB - Lei 9.394/96). Ele defende que, ao passo que o Estado promoveu a prioridade pelo ensino fundamental, se desobrigou dos outros níveis, especialmente do ensino superior público.

Durante o Plano Decenal de Educação para Todos (1993-2003), Pinto (2002) chama a atenção para os vetos realizados pelo então presidente Fernando Henrique Cardoso, especificamente para a meta de ampliação do ensino superior público, a criação do Fundo de Manutenção e Desenvolvimento da Educação Superior, a meta do financiamento público à pesquisa e, inclusive, o veto para ampliar programa de crédito educativo. Ou seja, uma intervenção que minou os mecanismos de ampliação do investimento público na educação superior, que estavam sendo demandados por aqueles setores que dependiam da educação pública.

Dito isto, vemos que o atual momento do FIES é um desdobramento de um processo histórico, que envolve interesses públicos e privados. Dessa forma, este artigo parte de uma retomada da conjuntura de surgimento do FIES, seu funcionamento e suas modificações ao longo do tempo. Na sequência apresentam-se os agentes privados, suas práticas em meio às sinalizações da política pública, bem como a concentração no setor. Por fim, o artigo traz considerações referentes aos efeitos da política do FIES na qualidade da educação e no comportamento dos agentes rentistas.

\section{Contexto nacional e o FIES}

O cenário econômico favorável ao Brasil na década passada (2000-2010) é um pontochave que propiciou a elevação da participação de mercado das Instituições de Ensino Superior (IES) privadas. Além disso, houve as alterações nas leis das universidades (iniciadas 
na década de 1990 $)^{4}$, que passaram a poder optar por serem entidades com fins lucrativos. Isso é também um ponto de grande influência do segmento. Outro ponto-chave determinante para o crescimento desse setor foi a concessão de crédito para financiar mensalidades em instituições privadas, voltada para a universalização do ensino superior, que vinha sendo desenhada de forma incipiente desde os mandatos de Fernando Henrique Cardoso, e passou por reformulações importantes no governo de Luiz Inácio Lula da Silva. Esse processo culminou em 2016 com desembolsos de R $\$ 19,18$ bilhões em recursos do FIES 5 .

O FIES foi criado em 1999 e instituído por meio da Lei 10.260 de 2001 pelo governo de Fernando Henrique Cardoso. É um fundo de financiamento de cursos superiores com avaliação positiva no Sistema Nacional de Avaliação da Educação Superior (Sinaes), do Ministério da Educação (MEC) (BRASIL, 2001). As avaliações no Sinaes têm notas de 1 até 5 , sendo considerada como positiva a obtenção de conceito maior ou igual a três, segundo critérios estipulados pelo artigo $1^{\circ}, \S 2^{a}$ da lei que cria o FIES. É, portanto, uma tentativa de garantir qualidade da oferta educativa.

Em atividade há duas décadas, o fundo tem passado por mudanças e alterações nos critérios para seleção dos contemplados com o empréstimo. Desde a sua criação sofreu 15 alterações na lei (BRASIL, 2017). Já houve atualizações na variação das taxas de juros cobradas, no volume de recursos disponibilizados pela União, percentual de financiamento, renda familiar, entre outras. O FIES, como fonte de financiamento dos matriculados, tornouse um ponto primordial na análise de desempenho das empresas de capital aberto, que precisam demonstrar regularmente em seus relatórios para onde ruma a atividade da empresa, de onde vêm as receitas e como será utilizado o dinheiro investido pelos acionistas. Desse modo, o FIES é visto como uma garantia para os investidores.

A universalização da educação superior privada pretendida pelo governo ganhou corpo, principalmente, por meio do incremento da verba do FIES, um enorme atrativo ao capital financeiro para o setor. A oportunidade para as companhias era explícita, porque os recursos do fundo tinham destino certo, as universidades privadas.

Em 2005, no primeiro mandato de Luiz Inácio Lula da Silva, houve uma remodelagem do fundo no sentido de aumentar a oferta de crédito por número de alunos e, assim, promover uma gradual universalização do ensino superior no Brasil. Em 2010, as taxas de juros foram reduzidas de $6,5 \%$ para 3,5\% ao ano, e o prazo para quitação após a conclusão do curso foi estendido. O país experimentava um ciclo econômico positivo, que perdurou até o início de 2014, que era caracterizado, entre outros fatores, pela elevação sistemática da renda da população, o que levou à melhora da qualidade de vida do brasileiro e fomentou a busca de

4 De acordo com Severino (2008), o decreto 2.026 de 1997, ao versar sobre entidades mantenedoras privadas de ensino superior, passa a nomear inclusive as de fins lucrativos. Ainda de acordo com o autor, outras medidas de políticas educacionais ampliam a participação dos agentes, haja vista o Plano Nacional de Educação de 2001, sem definição de ampliação de financiamento; o Plano de Desenvolvimento da Educação (PDE) de 2007, que estabelece o financiamento de bolsas pelo Programa Universidade para Todos (ProUni), e o Programa de Apoio a Planos de Reestruturação e Expansão das Universidades Federais (Reuni).

5 Em 2005, surge uma nova política pública, o Programa Universidade para Todos (ProUni), a qual não examinaremos no presente trabalho por se tratar de isenção fiscal. Os dois programas objetivavam a universalização no ensino superior, dentro de um pacote de ações afirmativas para a inclusão de classes menos favorecidas. 
melhorias pela população por cursos do ensino superior e acesso aos planos de saúde, por exemplo.

Até dezembro de 2016, o fundo funcionava assim: o aluno podia obter até $100 \%$ do valor da mensalidade. Ao longo do tempo de estudo e nos 18 meses subsequentes à formatura o aluno pagaria parcelas trimestrais de até $R \$ 150$. Após os 18 meses de carência (pósformatura), o contratante do crédito ganhava um prazo de três vezes o período do seu curso para pagar toda a dívida. Esse prazo podia ser de até 17 anos.

Conforme demonstrado, mediante modificações de ordem funcionais, o FIES como política pública, ainda que perdurando em arenas partidárias opositoras, seguiu seu processo de consolidação. Pautou-se na ampliação do acesso universitário a partir de uma lógica privatista, estimulando a ação de agentes privados na oferta de serviços de educação. Entre os anos 2003 e 2016 ocorreu a expansão de vagas na rede pública de ensino superior, a partir do Programa de Reestruturação e Expansão das Universidades Federais (Reuni) ${ }^{6}$, sendo esta uma lógica pautada no direito à educação pública e gratuita.

Antes de 2010, o financiamento era obtido mediante comprovação de renda e exigência de um percentual de presença dos alunos/as nos cursos nos quais se matriculavam. Após 2010 havia uma série de critérios para a entrada, como a participação de uma edição do Exame Nacional do Ensino Médio (Enem), tendo o solicitante obtido nota mínima de 450 pontos na média das provas e não podendo ter zerado a prova de redação, e a renda familiar mensal bruta (por pessoa) devia ser de até três salários mínimos. No entanto, a partir de 2013, devido ao crescimento do programa e de suas verbas, começou-se a se observar uma série de falhas e fragilidades. A partir de 2014, o governo começou a repensar a estrutura do FIES. Em janeiro de 2017, o Ministério da Educação do governo ilegítimo de Michel Temer realizou redução do teto global do financiamento, de $R \$ 42$ mil para $R \$ 30$ mil por semestre cursado, ou seja, um valor de até $\mathrm{R} \$ 5$ mil por mês, de acordo com reportagem do Estadão, do dia 6 de fevereiro de 2017.

Dados da publicação Análise Setorial da Educação Superior Privada, realizados pela consultoria Hoper (2016), estimam que a Educação Superior Privada teve receita líquida de $\mathrm{R} \$ 49,3$ bilhões em 2015. O panorama geral dado pela consultoria especializada em educação aponta um crescimento de $49,1 \%$ no número de matrículas totais do ensino superior no Brasil, ao passar de 5.250.147 de alunos, em 2007, para 7.828.013 em 2014 (HOPER EDUCAÇÃO, 2016, p. 12). Nas instituições privadas, o número passou de 3.914 .970 alunos para 5.867.011, em 2014 (alta de 49,8\%). Nas instituições públicas, as vagas passaram de 1.335.177, em 2007, para 1.961.002 (alta de 46,8\%).

Na publicação, a consultoria Hoper aponta um crescimento acentuado entre 2009 e 2014, apoiado na política de financiamento do governo federal (FIES) e no desempenho do setor de Ensino a Distância (EaD), e o aponta como o provável propulsor do crescimento do setor nos próximos anos no Brasil: "Em 2014, para cada 10 alunos da educação superior privada, pelo menos 2 alunos eram da educação a distância” (HOPER EDUCAÇÃO, 2016, p. 13). O relatório continua:

6 Programa do governo federal com o objetivo de expandir o acesso e a permanência na educação superior, a partir de diversas medidas, que vão desde a expansão de infraestrutura física, quadros acadêmicos e qualificação pedagógica. 
Em relação ao número de ingressantes na educação superior, por processo seletivo, o total registrado em 2014 foi de 2.802.497 alunos, que representa um aumento de $15,5 \%$ comparado a 2013. Os ingressantes em IES privadas atingiram o maior patamar da história, atingindo 2.307.988 alunos [...] A expectativa para 2015 e 2016 são percentuais mais baixos, considerando diminuição de contratos do Fies. Isso porque alunos com esses contratos chegam a compor $30 \%$ dos matriculados, dependendo da região ou da IES (HOPER EDUCAÇÃO, 2016, p. 18).

O documento indica que, em 2014, o financiamento, via programa do governo federal, foi responsável por $32 \%$ do mercado de graduação privada no Brasil (HOPER EDUCAÇÃO, 2016) deixando inúmeras IES vulneráveis ao orçamento estatal. Em 2015, os recursos do FIES deixam de ser repassados com a frequência mensal estabelecida até 2014, gerando críticas do mercado, sob a alegação de comprometimento dos caixas das IES privadas. Importante ressaltar que, dentro da Lei de Diretrizes e Bases da Educação (1996), o ensino realizado pelas instituições privadas deve atender a algumas condições, dentre elas, a "capacidade de autofinanciamento" (LDB - Art. 7), não podendo, dessa maneira, as instituições dependerem de recursos públicos.

Uma das principais falhas, do ponto de vista do aproveitamento dos recursos, é o fato de que, após a obtenção do financiamento, o que acontece na prática é que não há fiscalização do andamento e do aproveitamento do recurso público disponibilizado para o aluno - que vai direto para a tesouraria das IES privadas. Em maio de 2015, no mandato de Dilma Rousseff, a vice-presidente da Associação Nacional das Universidades Particulares (Anup), Elizabeth Guedes, apontou a falta de controle na fiscalização no programa de FIES, em audiência pública da Comissão de Educação da Câmara dos Deputados: "Algumas escolas têm mais de $70 \%, 80 \%$ de bolsas [...] o programa está fazendo o caixa de algumas escolas" (GUEDES, 2015, p. s/n).

Outro ponto é o limite de preço por mensalidade, o que permitia que a instituição cobrasse preços fora dos praticados pelo mercado. Depois da revisão pelo MEC em 2017, o limite da mensalidade por aluno passou a ser de até $\mathrm{R} \$ 5 \mathrm{mil}$, valor que pode ser considerado elevado se compararmos à exigência de entrada de renda familiar mensal bruta de até três salários mínimos por pessoa ( $R$ \$2.811, vigência do salário mínimo de $R \$ 937$ para o ano de 2017, de acordo com o Ministério do Trabalho). Ou seja, um fundo que pretende garantir acesso à educação superior para população de baixa renda, mas que, de fato, não oportuniza que os valores cobrados sejam acessíveis para essas famílias. Desse modo, parece que esse aumento está, sim, associado ao acesso de educação para classes de maior renda.

De acordo com Helena Sampaio (2017), pesquisadora na área de mercantilização e internacionalização do ensino superior, "[...] a formação dos grandes grupos educacionais foi possível graças ao financiamento público dos estudantes matriculados em IES privadas, por meio do FIES e do ProUni" (SAMPAIO, 2017, entrevista).

As mudanças iniciadas no sistema de ensino superior no Brasil, a partir de 1990, levaram a um forte processo de fusão e aglutinação de IES privadas com o objetivo de se transformarem em universidade. Como universidade, as IES gozam de autonomia administrativa (conferida pela Constituição de 1988) e sofrem menor influência do MEC, podendo, por exemplo, abrir e fechar cursos, aumentar e diminuir o número de vagas etc. (SAMPAIO, 2017). Essas iniciativas são favoráveis aos agentes privados, no entanto, trazem consequências para a oferta educativa. 


\begin{abstract}
Mais recentemente, na primeira década deste século, o processo de fusão e aglutinação de IES ganha novos contornos. Desde 1997, por lei, as mantenedoras de IES privadas podem escolher ter ou não finalidade lucrativa. Com isso, as IES tornaram-se uma mercadoria qualquer, podendo ser compradas e vendidas. Nesse processo de mercantilização, no qual as maiores passam a adquirir IES menores, grandes compram grandes IES, o capital financeiro entra nas grandes negociações e desenvolve-se um grande mercado de compra e venda de instituições de ensino superior. Algumas instituições colocam suas ações na Bolsa de Valores para serem negociadas etc. Consolidam-se grandes grupos educacionais, alguns com capital estrangeiro, que tendem a concentrar boa parte das matrículas de ensino superior no País (SAMPAIO, 2017, entrevista).
\end{abstract}

Segundo dados do Fundo Nacional de Desenvolvimento da Educação (FNDE), o valor do desembolso referente ao FIES no período de 2010 a 2016 foi de $R \$ 61,75$ bilhões. Essas informações foram concedidas pela Coordenação Geral de Suporte Operacional ao Financiamento Estudantil - CGSUP/DIGEF/FNDE, mediante pedido via Lei de Acesso à Informação (LAI). O FNDE não dispõe de dados relativos a períodos anteriores a 2010, visto que a Caixa Econômica Federal atuava como agente operador do FIES no período de 1999 a 2009 .

Se analisarmos ano a ano o incremento do desembolso, pode-se constatar que o potencial de crescimento das IES privadas, com base no número de alunos financiados por meio do fundo, era certeiro, salvo problemas de natureza administrativas das instituições. Fato é que os recursos estavam provisionados pelo governo federal, uma verba popularmente chamada de carimbada. Analisando os desembolsos do FIES, é possível verificar que as IES tiveram anos de grandes possibilidades, com um crescimento no volume de empréstimos da ordem de $2079,5 \%$, ao passar de $\mathrm{R} \$ 880$ milhões, em 2010, para $\mathrm{R} \$ 19,18$ bilhões em 2016, conforme pode ser verificado por meio do Fundo Nacional de Desenvolvimento da Educação (FNDE).

\title{
Um olhar sobre os agentes privados
}

No recorte por investimento recebido via FIES pelas empresas de educação superior listadas na bolsa, de 2010 até 2016, a Kroton ficou com a maior parcela dos recursos ( $R \$$ 4,058 bilhões) no período, a Anima angariou cerca de $\mathrm{R} \$ 1,36$ bilhão, seguida pela Ser Educacional, com R $\$ 1,524$ bilhão.

Os dados sobre a Estácio não foram informados pelo FNDE, tampouco pelo departamento de relações com investidores da instituição sob a alegação de que os recursos provenientes do FIES passaram a ser divulgados a partir de 2013, informados a partir de então nos releases de resultados. Após avaliação dos releases de resultados consolidados de 2010 até 2016 (ESTÁCIO, 2011-2017) chegou-se ao recebimento do montante de $R \$ 3,361$ bilhões em receita líquida, oriunda de recursos do FIES, no período pela Estácio. Sendo assim, a Estácio foi a segunda maior recebedora de recursos do programa de financiamento estudantil do governo federal, o FIES, no período analisado.

De acordo com Carvalho (2013) e Marques (2013), as mensalidades muitas vezes podem ficar acima da qualidade e retorno que o curso oferece. A má qualidade do ensino superior privado brasileiro é objeto de pesquisas acadêmicas na área da educação (CARVALHO, 2013; MANCEBO; VALE; MARTINS, 2015; SGUISSARDI, 2015; OLIVEIRA, 
2017), como uma consequência da massificação do ensino pelas redes, da falta de compromisso com a produção acadêmica de excelência e do acesso ao terceiro grau por uma boa parte de alunos cuja base educacional também é deficitária. Nossa entrevistada defende que

[...] é um modelo de negócio e o ensino superior no Brasil tornou-se um bom negócio. Há quem acredite que é possível ter uma maior padronização (e controle) da qualidade do ensino - tipo 'McDonald's' - o que é mais difícil com pequenas instituições (a cozinha da esquina) (SAMPAIO, 2017, entrevista).

A investida e o crescimento das IES privadas são fortalecidos, então, pelas fragilidades do FIES e o desleixo com o qual os agentes públicos fazem o acompanhamento da política pública de universalização do ensino superior; a melhora na renda média do brasileiro e as sinergias administrativas criadas pelos grupos. Os resultados podem ser constatados no avanço expressivo no número de matrículas privadas.

Entre 2001 e 2010 as matrículas nas instituições públicas aumentaram de 944.584 para 1.643.298, a uma taxa de $42,5 \%$. Já as matrículas nas instituições privadas aumentaram neste mesmo período de 2.091.529 para 4.736 .001 em 2010, a uma taxa de 55,8\%, bastante superior à taxa de crescimento das instituições públicas. Esta diferença adquire significado mais forte devido ao fato de que as matrículas na educação superior privada correspondem a $3 / 4$ do total das matrículas, diferença que vem se mantendo constante desde 2006. Quantitativamente, portanto, a taxa de crescimento da matrícula aliada ao volume da matrícula na educação superior privada sinaliza forte aumento de poder e influência nos rumos da educação superior no país [...] Em 2010, 74.2\% das matrículas estão no setor privado, e 25.8\% estão no setor público (MARQUES, 2013, p. 72).

Outro ponto preocupante: em um país com um baixo grau de educação financeira, é possível constatar que muitas vezes o aluno começa a dívida sem saber quanto terá de pagar quando terminar o financiamento e como isso será feito. Esse é o entendimento do analista Tiago Ring, especializado no FIES:

Um aluno carente prefere estudar antes e, depois de terminar o curso, ele vê como fará para pagar. Não há planejamento e as faculdades fazem o seu papel no mercado, vendem o sonho. Depois que começou a crescer o volume financiado houve a perda do controle e da sustentabilidade do programa. $E$ as empresas cresceram com isso e com o fato de a fiscalização ser ineficaz (RING, 2017, entrevista).

Ring afirma que, antes de o FIES ganhar o volume de recursos ao qual chegou (R\$ 19,18 bilhões em 2016, FNDE), os preços das mensalidades eram condizentes com a realidade, mas depois começou o disparate. Ele explica que o setor de educação no Brasil não era atrativo até as mudanças recentes no FIES, de 2005 e 2010:

Acabou com inadimplência para as escolas, instituições não sofrem mais com isso e o mercado se acelerou fortemente entre 2011 e 2014. As empresas não precisavam mais oferecer desconto porque a maior parte das mensalidades vinha do FIES, os preços subiram muito acima da inflação. Com isso, o setor ficou atrativo e houve pouco acompanhamento da forma como os desembolsos eram feitos, da efetiva formação do aluno (RING, 2017, entrevista).

Milhares de estudantes brasileiros recebem do governo federal financiamento estudantil e esse número cresceu expressivamente na última década. O FIES é o principal meio utilizado por alunos que não têm recursos para pagar a faculdade privada e tampouco conseguem 
passar pela peneira dos processos de seleção das instituições públicas, por causa de uma série de fatores, como o ensino público precário nas escolas em todos os níveis. De acordo com Dayane Sousa (2016, p. 5):

Além da concessão de bolsas, foram alteradas, a partir de 2010, as regras para a oferta de crédito estudantil no programa Fundo de Financiamento Estudantil [...] A partir de então, a quantidade de contratos de financiamento firmados aumentou semestre a semestre até o final de 2014, segundo dados do Fundo Nacional de Desenvolvimento da Educação.

Em 2014 ocorreu uma freada brusca no FIES, que passa a ser computado no planejamento das empresas para o ano seguinte, com recuo intenso no preço das ações na bolsa de valores. À época, as regras para nota de corte e as condições para o desembolso às Instituições de Ensino Superior privadas foram elevadas. Até essa mudança, os repasses dos programas para as tesourarias das IES eram feitos mensalmente, mas depois, com a crise fiscal federal que se anunciava, o governo de Dilma Rousseff decidiu fazer os pagamentos em oito parcelas. Esse movimento geraria um grande impacto no fluxo de capital das empresas. Segundo a autora Bárbara Libório (2015):

As IES mais expostas aos riscos são as mais dependentes da receita do programa. 'Tem escola em que $90 \%$ dos contratos de matrícula são do FIES. Essas vão ser duramente atingidas, mas o FIES não foi feito para alavancar a receita. No FIES, a inadimplência não existe, não tinha nota de corte e alunos com baixas médias podiam entrar. Muitos gestores, por incompetência ou má fé, têm alto risco de exposição ao FIES e sentirão bastante. E é certo. O FIES não é feito para alavancar receita', afirma Elizabeth Guedes, diretora-executiva da Associação Brasileira para o Desenvolvimento da Educação Superior (Abraes).

A alteração de 2014 das regras do FIES provocou um grande transtorno no ciclo financeiro dessas empresas e na capacidade de previsão das entradas de recursos oriundos do FIES. Se as IES privadas recebiam mensalmente os valores dos bolsistas, a regra foi mudada colocando o planejamento orçamentário em xeque e adiando a entrada de proventos esperados. Dayane Sousa (2016, p. 5) explica que:

[...] a expansão do FIES foi um dos fatores que contribuiu para a expansão de grandes grupos de ensino superior privado, sendo possível observar o crescimento da relevância do FIES nessas companhias no período. A alteração, em 2015, no programa do governo, porém, cria um novo cenário para o setor. Ao longo de 2015, foram firmados aproximadamente 313 mil novos contratos do FIES uma retração ante os $732 \mathrm{mil}$ contratos novos de 2014 (BRASIL, 2015). Essa diminuição de oferta de vagas no programa de financiamento público teve impactos para as companhias do setor, que passaram a conviver com uma desaceleração no crescimento das matrículas de novos alunos, conforme dados das companhias de capital aberto.

O resultado dessa modificação foi a insegurança do mercado e a fuga expressiva de acionistas em 2015, o que derrubou o preço dos papéis na bolsa de valores e causou uma desconfiança momentânea no setor, como mostra a tabela abaixo. 
Tabela 1 - Comportamento das ações após alterações no FIES (2014 e 2005)

\begin{tabular}{ccccc}
\hline Datas & Código & Nível & Preço último (RS) & Var. (\%) \\
\hline $30 / 12 / 2014$ & ANIM3 & NM & 35,35 & 67,48 \\
\hline $30 / 12 / 2015$ & ANIM3 & NM & 13,8 & $-59,74$ \\
\hline $30 / 12 / 2014$ & KROT3 & NM & 15,5 & 63,76 \\
\hline $30 / 12 / 2015$ & KROT3 & NM & 9,53 & $-37,54$ \\
\hline $30 / 12 / 2014$ & SEER3 & NM & 29,59 & 27,35 \\
\hline $30 / 12 / 2015$ & SEER3 & NM & 7,7 & $-73,88$ \\
\hline $30 / 12 / 2014$ & ESTC3 & NM & 20,72 & 17,73 \\
\hline $30 / 12 / 2015$ & ESTC3 & NM & 12,35 & $-40,39 \%$ \\
\hline \multicolumn{5}{c}{ Fonte: BM\& Bovespa e CMA. } \\
\hline
\end{tabular}

Conforme pode ser constatado na tabela anterior, os valores das ações negociadas no fechamento do ano de 2014, em comparação com o final de 2015, sofreram forte redução nas quatro IES, sendo a maior variação nas ações da Ser Educacional, com queda de aproximadamente $73 \%$ em relação ao ano anterior.

Para o Conselho Administrativo de Defesa Econômica (CADE), os programas de financiamento do ensino superior voltados para promover o acesso para parte da população com menor nível de renda, bem como apoiar a reestruturação das instituições de ensino superior "[...] foram fundamentais na expansão da base de alunos do ensino superior na última década e, por consequência, na expansão das próprias empresas que atuam na atividade de educação superior" (CADE, 2016, p. 17).

No entanto, como demonstra a Kroton em seu balanço de resultados 2016, o fluxo de desembolso do FIES nas instituições segue normalizado, sem causar impactos nas contas a receber das instituições.

Conforme Securato et al. (apud Sousa, 2016, p. 19), há aí um custo de natureza explícita. Se existe um incremento de receita e de diluição de custos, em especial no caso de companhias com estrutura de custos fixos mais altos em relação aos custos variáveis, há também, por outro lado, um custo de destinar recursos para financiamento a clientes. Como defende o autor:

Trata-se do custo de investimento em valores a receber. Há também um custo de oportunidade do próprio capital. Esse custo pode ser entendido como derivado de uma escolha, uma vez que pode haver a possibilidade de que os montantes alocados em valores a receber pudessem ser remanejados para ativos mais rentáveis (SECURATO et al. apud SOUSA, 2016, p. 19).

Percentualmente em relação à base total de alunos da graduação, o FIES representou $38,7 \%$ dos alunos da Anima, seguidos de $22,7 \%$ dos da Estácio, $21,8 \%$ da Kroton e $5,8 \%$ da Ser Educacional. As informações constam dos balanços das companhias avaliadas (ANIMA, 2017; ESTÁCIO, 2017; KROTON, 2017; SER EDUCACIONAL, 2017).

Outra importante fonte de recursos estatal é o Programa Universidade Para Todos (ProUni). Não chega a ser investimento federal direto, mas o estado deixa de arrecadar para transformar esse tipo de receita em vagas para a população economicamente vulnerável em 
instituições privadas. Segundo a Secretaria de Educação Superior, em contrapartida às bolsas ofertadas, as instituições de ensino superior participantes do Programa Universidade Para Todos (ProUni) recebem isenção de impostos e contribuições, conforme disposto no art. $8^{\circ}$ da Lei $n^{\circ} 11.096$, de 13 de janeiro de 2005, não havendo dispêndio de recursos do orçamento do Ministério da Educação para pagamento de valor individual das bolsas concedidas no âmbito do programa ou de repasse direto às instituições.

O Programa do Ministério da Educação (MEC) foi criado em 2004 e oferece bolsas para alunos que fizeram ensino médio na rede pública, ou bolsistas de particulares e estudantes com deficiência integrais ou parciais $(50 \%)$ para cursos de graduação e sequenciais de formação específica. Além desse público, o ProUni oferece bolsas para professores da rede pública de ensino. Bolsistas integrais obedecem a regra da renda familiar de até um salário mínimo e meio por pessoa ( $R \$ 1.405,5$, salário mínimo em 2017); bolsistas parciais, a renda bruta per capita deve ser de até três salários mínimos $(R \$ 2.811)$.

Nesse sentido, a implementação do FIES e do ProUni, como políticas públicas para a expansão de vagas na educação, gerou repercussões no mercado de ensino superior privado. Na sequência, realizar-se-á um olhar mais detido sobre tais efeitos.

\section{Efeitos do FIES no setor}

Em consonância à observação dos pesquisadores e educadores supracitados, a análise e a forma como o Conselho Administrativo de Defesa Econômica (CADE) acompanha as movimentações no setor educacional brasileiro corrobora com a tese de concentração de mercado. Esse fato demonstra objetivamente, por meio do agente legal de acompanhamento concorrencial, que os conglomerados impõem dificuldades à livre concorrência e contrariam a lei 12.529 , de 30 de novembro de 2011, que trata, entre outros aspectos, da atividade concorrencial brasileira.

Atento a isso, em maio de 2016, o Conselho publicou o caderno intitulado Atos de Concentração no Mercado de Prestação de Serviços de Ensino Superior. A saber, essa é a terceira publicação analítica voltada ao grande público; a primeira foi sobre o Varejo de Gasolina e a segunda sobre a conduta do Mercado de Saúde Suplementar. Na publicação sobre a concentração das IES privadas, consta um histórico das análises de fusões e aquisições deste mercado e fica detalhada a necessidade de mudança de metodologia de acompanhamento pelo órgão (antes feita apenas pelo número de matrículas por instituição, tendo sido modificada quatro anos antes com acréscimo da avaliação da capacidade de penetração regional das empresas e a pulverização das atividades de ensino a distância EaD), em decorrência da movimentação veloz e consequente concentração por parte dos grandes grupos, como Kroton, Estácio, Ser Educacional e Anima. Todas essas empresas são objeto de análise da publicação referida:

\footnotetext{
A relevância do tema reside no fato de que a intensidade das mudanças nos mercados de educação superior em um período relativamente curto $-80 \%$ dos atos de concentração ocorreram entre os anos de 2008 e 2013 - exigiu deste Conselho respostas rápidas em termos de atualização de conhecimentos e métodos analíticos (CADE, 2016, p. 5).
}

Além da análise, a publicação apresenta todo o processo de mudança pelo qual o setor educacional privado passou desde os anos de 1990, e a evolução das Instituições de Ensino 
Superior privadas. O órgão, que é vinculado ao Ministério da Justiça e tem como função zelar pela livre concorrência entre as empresas no Brasil, detém atenção especial para o período de 2008 até 2013, período no qual as demandas e denúncias feitas ao Conselho Administrativo de Defesa Econômica (CADE) cresceram.

Para Sampaio (2017), desde o final dos anos 1990 existe, no sistema de ensino superior no Brasil, um forte processo de fusão e aglutinação de Instituições de Ensino Superior privadas com o objetivo de se transformarem em universidade. Segundo a autora:

Como universidade, as IES gozam de autonomia administrativa (conferida pela Constituição de 1988) e se veem livres do MEC, podendo, por exemplo, abrir e fechar cursos, aumentar e diminuir o número de vagas etc. Todas essas iniciativas são importantes para o setor privado de ensino superior. Mais recentemente, na primeira década deste século, o processo de fusão e aglutinação de IES ganha novos contornos. Desde 1997, por lei, as mantenedoras de IES privadas podem escolher ter ou não finalidade lucrativa. Com isso, as IES tornaram-se uma mercadoria qualquer, podendo ser compradas e vendidas. Nesse processo de mercantilização, em que as IES maiores passam a adquirir IES menores, grandes IES compram grandes IES, o capital financeiro entra nas grandes negociações e desenvolve-se um grande mercado de compra e venda de instituições de ensino superior. Algumas instituições colocam suas ações na Bolsa de valores para serem negociadas etc. Consolidam-se grandes grupos educacionais, alguns com capital estrangeiro, que tendem a concentrar boa parte das matrículas de ensino superior no País (SAMPAIO, 2000, p. 72).

O desembolso do governo federal com o FIES para a promoção da universalização do ensino superior, de acordo com dados obtidos pela Lei de Acesso à Informação (LAl), foi de $\mathrm{R} \$ 61,75$ bilhões no acumulado de 2010 até $2016^{7}$.

Os Fundos ainda realizaram novos aportes em educação, segundo a reportagem do jornal Valor Econômico (2017). Em 2015, os fundos internacionais detinham participações de $38 \%$ do capital total da Estácio e de $20 \%$ na Kroton, e um dos chamarizes a esses investidores era as somas vultosas do FIES. O texto chama a atenção ainda para o fato de que:

Essas investidas dos fundos estrangeiros são explicadas porque o valor dos papéis das companhias de educação teve uma forte queda neste ano devido às mudanças nas regras do FIES, programa de financiamento estudantil do governo. Segundo as gestoras de private equity, os investimentos em educação foram mantidos porque no longo prazo há um potencial de ganho, uma vez que no Brasil apenas $15 \%$ dos jovens entre 18 e 24 anos estão no ensino superior e a meta do governo é dobrar esse percentual em 2025 [...] A primeira rodada de investimentos no setor de educação ocorreu entre 2007 e 2010, quando houve um boom de IPOs (aberturas de capital). Neste período, Pátria, GP, Advent e BR Investimentos (atual Bozano) investiram na Anhanguera, Estácio, Kroton e Abril Educação que se tornaram os maiores grupos de ensino do país. Essas gestoras fizeram seus desinvestimentos há dois anos com ganhos expressivos. Em setembro de 2013, por exemplo, a Advent vendeu 1,8\% do capital da Kroton por cerca de R\$200 milhões. Atualmente, os fundos com maior tempo de permanência são o americano Capital Group, que adquiriu 35\% do lbmec por R\$130 milhões em 2010, e a gestora inglesa Actis que pagou $\mathrm{R} \$ 180$ milhões por uma fatia de $37 \%$ da Cruzeiro do Sul em 2012 (KOIKE, 2015, online).

7 Os dados solicitados abrangiam o período de 2007 até 2016, no entanto, o respondente do questionamento, o Fundo Nacional de Desenvolvimento da Educação (FNDE), passou as informações desde que assumiu a atribuição de Agente Operador do FIES a partir da publicação da Lei no 12.202, de 2010. 
Para pesquisadores e analistas de mercado, no entanto, a fragilidade e falta de fiscalização sobre a forma como o crédito educativo é gerido no Brasil leva a uma sucessão de equívocos, atrai investidores que buscam apenas o lucro oriundo da IES e não garante qualidade do ensino.

Sampaio (2017) afirma que a formação dos grandes grupos educacionais foi possível graças ao financiamento público dos estudantes matriculados em IES privadas, por meio do FIES e do ProUni. Para a autora, o financiamento deve ser para o estudante e não para a instituição de ensino superior.

Durante os anos de análise compreendidos pela CADE, foram analisados 62 atos de concentração:

A participação dos fundos de investimentos no capital social de empresas de educação traz implicações para a análise concorrencial empreendida pelo Cade, não só pelo aumento das concentrações de mercado decorrentes dos processos de compra de concorrentes, como também pela necessidade de se atentar para a possibilidade de tais fundos terem participação em outras empresas concorrentes ou, ainda, participantes de outros estágios da cadeia produtiva capazes de gerar um processo de integração vertical com as instituições de ensino superior (CADE, 2016, p. 24).

$\mathrm{Na}$ análise da consultoria educacional Hoper (2017), quem aproveitou o crescimento da oferta do FIES entre 2012 e 2014, principalmente, foram as IES consolidadoras do setor de ensino. Elas ainda conseguiram utilizar outras estratégias para minimizar os impactos das restrições do FIES e da crise econômica. Já as IES não consolidadoras, não conseguiram o mesmo desempenho e muitas delas sofreram mais os efeitos dessa crise.

\begin{abstract}
O fenômeno de concentração de mercado no setor de educação privada no Brasil é uma realidade, que não terá retrocesso. Há 13 anos, os 20 maiores grupos educacionais detinham em torno de $14 \%$ do mercado, em relação ao total de alunos. Em 2015, estimamos que os 12 principais grupos educacionais concentram $43,9 \%$ da quantidade de matrículas em cursos de graduação superior (Presencial e EaD) e Pós-graduação. Em receita líquida, a estimativa de participação destes 12 grupos atinge o valor de $35,8 \%$ (HOPER EDUCAÇÃO, 2016, p. 102).
\end{abstract}

A análise apresentada evidencia a atuação do poder público, bem como dos agentes privados, evidenciando como a política pública e a ação dos agentes financeiros possui uma inter-relação. Na sequência, à guisa de conclusão, retoma-se os efeitos desta dinâmica no setor de educação superior privado e na educação entre os anos de 2010 e 2016.

\title{
Considerações finais
}

O capital financeiro, rentistas acumuladores de capitais e fundos de investimentos viveram recentemente dias de glória, fortunas em dividendos oriundos da pujante atividade rumo à universalização do ensino superior proposta por uma política pública que deixou patente o repasse de dinheiro público à iniciativa privada, sem fiscalização ou busca pela qualidade do serviço. O Estado literalmente encheu os cofres das tesourarias das Instituições de Ensino Superior privadas com R\$ 61,75 bilhões em recursos do FIES de 2010 até 2016. Esse montante é bem próximo aos investimentos federais totais para o ano de 2016 (que incluem obras públicas e a compra de equipamentos), que foi de $R \$ 64,92$ bilhões, segundo dados do Banco Central do Brasil. 
Até 2014, as empresas de educação eram as mais atrativas para os investidores da BM\&FBovespa, porque tinham um negócio em franca expansão, financiado em boa parte pelo governo federal. Acionistas, mercado e fundos aproveitaram o período recente para se capitalizar e distribuir dividendos. O reflexo dessa bonança não foi sentido na qualidade do serviço oferecido, segundo pesquisadores ouvidos e estudos acadêmicos consultados, mas deixou explícito que houve uma industrialização dos diplomas mediante a alta expressiva no número de estudantes que acessavam o ensino superior buscando qualificação, com foco na melhora do nível de vida, emprego e renda.

O presente trabalho é importante na proposição para a reflexão sobre como o processo de fusão e aquisição das empresas de educação listadas na bolsa orientou as práticas empresariais que levaram à aglutinação de grandes grupos. Além disso, a proposta é pensar qual a importância e o peso dos recursos públicos, via financiamento estudantil, no fomento das atividades financeiras e no processo de profissionalização desses grupos.

A falta de sustentabilidade do FIES, situação observada mais fortemente no mandato de Dilma Rousseff, é óbvia para analistas de mercado e pesquisadores. Em fevereiro de 2017, após derrubada do governo Dilma, dentre diversas mudanças políticas, o Ministério da Educação (MEC) anunciou a redução de $29 \%$ dos investimentos no FIES.

\begin{abstract}
O secretário de Acompanhamento Econômico do Ministério da Fazenda, Mansueto Almeida, afirmou que uma equipe de trabalho da Pasta, em parceria com o MEC, estuda o programa desde julho do ano passado e identificou diversos problemas. 'O programa do jeito que está hoje tem um risco fiscal muito grande. Se o governo não consertar agora vai correr risco de o programa ser descontinuado [...] Tudo está sendo feito para evitar esqueletos no futuro', avaliou Mansueto. O secretário anunciou que será formado um comitê interministerial do FIES para garantir mais transparência dos subsídios. 'Crédito educativo é bom, o problema é que o programa foi mal desenhado', criticou. Segundo ele, houve um crescimento muito 'rápido e forte' nos investimentos do programa entre 2010 e 2014 (ENTIDADE..., 2017, online).
\end{abstract}

Um dos motivos apresentados pelo Executivo era o fato de os investimentos não serem sustentáveis. Agora o setor financeiro, acionistas e fundos precisam equacionar a médio e longo prazo como manter tão lucrativas e sustentáveis suas atividades após o principal financiador do ensino superior privado - a União - ter começado um movimento de diminuição dos desembolsos, o que em 2015 já causou grande estrago. Os analistas viram e apontaram isso. O mercado aproveitou muito enquanto pôde; não é possível afirmar que não se viu tudo isso, pois está fartamente documentado.

Por fim, a aposta do FIES por intermédio das IES privadas, beneficiou instituições que, em grande medida: perpetuam cursos de graduação de baixo desempenho nas avaliações governamentais; pautam sua oferta majoritariamente em apenas um dos pilares da educação, que é o ensino (perdendo a projeção da pesquisa e da extensão); advogam pela tratativa da educação como uma mercadoria; e buscam o fortalecimento de marcas de educação, em detrimento do processo educativo.

Esta é uma dinâmica em curso, no entanto, seu percurso até aqui tem apontado para alternativas de expansão da educação superior que tem promovido precarização da educação e o fortalecimento insustentável de agentes privados. Nesse sentido, urgem mudanças, seja por uma perspectiva de educação de qualidade, seja, até mesmo, por uma perspectiva mais liberal. 
Educação na Bolsa de Valores

\section{Referências}

ANIMA EDUCAÇÃO S.A. Demonstrações Financeiras Individuais e Consolidadas Referentes ao Exercício Findo em 31 de Dezembro de 2016. Belo Horizonte, 2017. Disponível em: < http://ri.animaeducacao.com.br/>. Acesso em: 14 mar. 2017.

ASSOCIAÇÃO BRASILEIRA DE PRIVATE EQUITY \& VENTURE CAPITAL (ABVCAP). Como Funciona a indústria de Private Equity, Seed e Venture Capital? São Paulo, 2015.

BANCO CENTRAL DO BRASIL. Histórico das Taxa de Juros. Banco Central do Brasil, 2017. Disponível em: <https://www.bcb.gov.br/Pec/Copom/Port/taxaSelic.asp>. Acesso em: 8 fev. 2017.

BOLSA DE MERCADORIA E FUTUROS BOVESPA, BM\&FBOVESPA. ASSESSORIA DE IMPRENSA. Empresas Educação - TCC MBA BM\&FBovespa. [mensagem pessoal] Mensagem recebida em 10 fev., 2017.

BRASIL. Lei n 9.394/96, de 20 de dezembro de 1996. Lei de Diretrizes e Bases da Educação. Diário Oficial da União, Brasília, 1996.

BRASIL. Lei no 10.260, de 12 de julho de 2001. Dispõe sobre o Fundo de Financiamento ao estudante do Ensino Superior e dá outras providências. Diário Oficial da União, Brasília, 2001. Disponível em: <http://www.planalto.gov.br/ccivil_03/leis/LEIS_2001/L10260.htm>. Acesso em: 3 mar. 2017.

BRASIL. Lei no 12.529, de 30 de novembro de 2011. Diário Oficial da União, Brasília, 2011.

BRASIL. Ministério da Educação. Portal do Programa Universidade para Todos. Brasília, 2016. Disponível em: <http://siteprouni.mec.gov.br/>. Acesso em: 8 mar. 2017.

CÂMARA DOS DEPUTADOS. Representante de universidades particulares aponta falta de fiscalização no Fies. Distrito Federal, fev. 2017. Disponível em: <http://www2.camara.leg.br/camaranoticias/noticias/EDUCACAO-E-CULTURA/488528REPRESENTANTE-DE-UNIVERSIDADES-PARTICULARES-APONTA-FALTA-DEFISCALIZACAO-NO-FIES.html>. Acesso em: 3 mar. 2017.

CARVALHO, Cristina Helena Almeida de. A mercantilização da educação superior brasileira e as estratégias de mercado das instituições lucrativas. Revista Brasileira de Educação, Brasília, v. 18, n. 54, jul./set. 2013.

CONSELHO ADMINISTRATIVO DE DEFESA ECONÔMICA - CADE. Atos de Concentração no Mercado de Prestação de Serviços de Ensino Superior. Brasília, maio 2016.

CONSELHO ADMINISTRATIVO DE DEFESA ECONÔMICA - CADE. SuperintendênciaGeral conclui parecer sobre operação entre Kroton e Estácio. Distrito Federal, fev. 2017. Disponível em: <http://www.cade.gov.br/noticias/superintendencia-geral-conclui-parecersobre-operacao-entre-kroton-e-estacio>. Acesso em: 3 mar. 2017.

CUNHA, Luiz Antônio; GÓES, Moacyr de. O golpe na educação. São Paulo: Editora Zahar, 2002.

ENTIDADE de educação privada pede que Cade rejeite fusão de Kroton e Estácio. Jornal do Comércio, Porto Alegre, 2017. Disponível em: <http://jcrs.uol.com.br/ 
conteudo/2017/02/economia/547539-entidade-de-educacao-privada-pede-que-cade-rejeitefusao-de-kroton-e-estacio.html> Acesso em: $18 \mathrm{fev} .2017$.

ESTÁCIO PARTICIPAÇÕES S.A. Demonstrações Financeiras Individuais e Consolidadas Referentes ao Exercício Findo em 31 de Dezembro de 2016. Rio de Janeiro, 2017. Disponível em: <http://www.estacioparticipacoes.com.br>. Acesso em: 15 mar. 2017.

GOVERNO anuncia redução de $29 \%$ nos investimentos do Fies. Portal Uol, 2017. Disponível em: <https://educacao.uol.com.br/noticias/agencia-estado/2017/02/06/governo-anunciareducao-de-29-nos-investimentos-do-fies.htm> Acessado em: 6 fev. 2017.

HILL, Dave. O neoliberalismo global, a resistência e a deformação da educação. Currículo sem Fronteiras, Brasil; Portugal; Estados Unidos, v. 3, n. 2, p. 24-59, jul./dez. 2003.

HOPER EDUCAÇÃO. Análise Setorial da Educação Superior Privada 2016. Foz do Iguaçu, jun. 2016.

KOIKE, Beth. Fundos fazem novos aportes em educação. Valor Econômico, 2015. Disponível em: <http://www.valor.com.br/empresas/4287786/fundos-fazem-novos-aportesem-educacao>. Acesso em: 5 jan. 2017.

KROTON EDUCACIONAL S.A. Demonstrações Financeiras Individuais e Consolidadas Referentes ao Exercício Findo em 31 de Dezembro de 2016. Belo Horizonte, 2017. Disponível em: <http:///ri.kroton.com.br>. Acesso em: 22 mar. 2017.

LIBÓRIO, Bárbara. Grupos de ensino negociam Fies para evitar caixa apertado. Portal iG, 2015. Disponível em: <http://economia.ig.com.br/2015-02-02/grupos-de-ensino-negociamfies-para-evitar-caixa-apertado.html>. Acesso em: 15 dez. 2016.

MANCEBO, Deise; VALE, Andréa Araújo do; MARTINS, Tânia Barbosa. Políticas de expansão da educação superior no Brasil (1995-2010). Revista Brasileira e Educação, Rio de Janeiro, v. 20. n. 60, p. 31-50, jan.-mar. 2015.

MARQUES, Waldemar. Expansão e oligopolização da educação superior no Brasil. Avaliação (Campinas), Sorocaba, v. 18. n. 1, p. 69-83, mar. 2013.

OLIVEIRA, Romualdo Portela de. A financeirização da economia e suas consequências para a educação superior no Brasil. In: Gilberto Maringoni (Org.). O negócio da Educação. São Paulo: Olho D'água, 2017, v. 1. p. 27-35.

PINTO, José Marcelino. Financiamento da educação no Brasil: um balanço do governo FHC (1995-2002). Educação e Sociedade, Campinas, v. 23, n. 80, set. 2002.

PORTAL DA TRANSPARÊNCIA NOS RECURSOS PÚBLICOS FEDERAIS. Portal da transparência do Governo Federal. 2014. Disponível em: <http://www.portaldatrans parencia.gov.br/> Acesso em: 01 fev. 2017.

RING, Tiago. Entrevista concedida a Maíra Teixeira da silva. São Paulo. 7, fev. 2017.

SAMPAIO, Helena. Ensino superior no Brasil - o setor privado. São Paulo: Hucitec/Fapesp, 2000. 
SAMPAIO, Helena. Privatização do ensino superior no Brasil: velhas e novas questões. In: SCHWARTZAMAN, Simon (Org.) A educação superior na América Latina e os desafios do século XXI. Campinas: Editora da Unicamp, 2014.

SAMPAIO, Helena. Entrevista concedida a Maíra Teixeira da Silva. São Paulo, 22, jan. 2017. SECURATO, José Roberto et al. Crédito: Análise e avaliação do risco. São Paulo: Saint Paul Editora, 2007.

SER EDUCACIONAL S.A. Demonstrações Financeiras Individuais e Consolidadas Referentes ao Exercício Findo em 31 de Dezembro de 2016. Recife, 2017. Disponível em: $<$ http://ri.sereducacional.com>. Acesso em: 17 mar. 2017.

SER EDUCACIONAL S.A. Portal Relações com Investidores. Recife, 2017. Disponível em: $<$ http://ri.sereducacional.com/sereducacional/web/conteudo_pt.asp?idioma=0\&conta=28\&tip o=47915>. Acesso em: 6 mar. 2017.

SEVERINO, Antônio. O ensino superior brasileiro: novas configurações e velhos desafios. Educar em Revista, Curitiba, n. 31, p. 73-89, jan.-jun. 2008.

SGUISSARDI, Valdemar. Educação Superior no Brasil: democratização ou massificação mercantil? Educação e Sociedade, Campinas, v. 36, n. 133, p. 867-889, out.-dez. 2015.

SISTEMA DE ACESSO À INFORMAÇÃO. E-SIC. Coordenação Geral de Suporte Operacional ao Financiamento Estudantil - CGSUP/DIGEF/FNDE, mediante pedido via Lei de Acesso à Informação (LAI). 2016, 2017. Disponível em: <https://esic.cgu.gov.br/sistema/ site/index.html>. Acesso em: 01 nov. 2016.

SOUSA, Dayanne. Crédito estudantil privado após o novo Fies: desafios e oportunidades. Monografia (Pós-Graduação Lato Sensu, MBA informações econômico-financeiras e mercado de capitais para jornalistas) - Faculdade UBS, UBS Escola de Negócios, São Paulo, 2016.

Maíra Teixeira Silva é graduada em Jornalismo pela Universidade Anhembi Morumbi e pósgraduada em Informações Econômico-financeiras e Mercado de Capitais para Jornalistas pela UBS Escola de Negócios e BM\&F Bovespa.

ORCID: http://orcid.org/0000-0002-8919-4969

E-mail:mairats@hotmail.com

Felipe Furini Soares é mestrando em Ciências Humanas e Sociais pela Universidade Federal do $A B C$ (UFABC), licenciado em Ciências Sociais pela Universidade Federal da Paraíba (UFPB), bacharel em Administração de Empresas e especialista em Gestão de Organizações do Terceiro Setor (Mackenzie/SP) e especialista em Desenvolvimento Local e Regional pela (Universidad de Los Andes - Colômbia).

ORCID: http://orcid.org/0000-0002-7997-5550

E-mail: felipefurini@gmail.com 


\section{Editores do volume 9}

José Marcelino de Rezende Pinto - Universidade de São Paulo, São Paulo/SP, Brasil

Nalú Farenzena - Universidade Federal do Rio Grande do Sul, Porto Alegre/RS, Brasil

\section{Comitê Editorial}

José Marcelino de Rezende Pinto - Universidade de São Paulo, Brasil

Juca Gil - Universidade Federal do Rio Grande do Sul, Brasil

Theresa Adrião - Universidade Estadual de Campinas, Brasil Ângelo

Ricardo de Souza - Universidade Federal do Paraná, Brasil

Márcia Aparecida Jacomini - Universidade Federal de São Paulo, Brasil

\section{Conselho Editorial}

\section{Alejandro Morduchowicz}

Universidad Pedagógica, Provincia de Buenos Aires, Argentina

Fernanda Saforcada

Universidade de Buenos Aires, Argentina

Jacques Velloso

Universidade de Brasília, Brasil

João Monlevade

Senado Federal, Brasil

Jorge Abrahão de Castro

Instituto de Pesquisa Econômica Aplicada / IPEA, Brasil

Juca Gil

Universidade Federal do Rio Grande do Sul, Brasil

Lisete Regina Gomes Arelaro

Universidade de São Paulo, Brasil

Luis Carlos Sales

Universidade Federal do Piauí, Brasil

Luiz de Sousa Junior

Universidade Federal da Paraíba, Brasil

Luiz Fernandes Dourado

Universidade Federal de Goiás, Brasil

Magna França

Universidade Federal do Rio Grande do Norte, Brasil

\section{Maria Beatriz Luce}

Universidade Federal do Pampa, Brasil

Universidade Federal do Rio Grande do Sul, Brasil

Marcos Edgar Bassi

Universidade Federal de Santa Catarina, Brasil

\author{
Maria Dilnéia Espíndola Fernandes \\ Universidade Federal de Mato Grosso do Sul, Brasil \\ Nalú Farenzena \\ Universidade Federal do Rio Grande do Sul, Brasil \\ Nelson Cardoso do Amaral \\ Universidade Federal de Goiás, Brasil \\ Nicholas Davies \\ Universidade Federal Fluminense, Brasil \\ Rosana Evangelista Cruz \\ Universidade Federal do Piauí, Brasil \\ Rosana Gemaque \\ Universidade Federal do Pará, Brasil \\ Robert E. Verhine \\ Universidade Federal da Bahia, Brasil \\ Romualdo Portela de Oliveira \\ Universidade de São Paulo, Brasil \\ Theresa Adrião \\ Universidade Estadual de Campinas, Brasil \\ Tristan McCowan \\ University of London, Reino Unido \\ Vera Jacob \\ Universidade Federal do Pará, Brasil \\ Vera Peroni \\ Universidade Federal do Rio Grande do Sul, Brasil \\ Vitor Henrique Paro \\ Universidade de São Paulo, Brasil
}

\section{Equipe editorial}

Apoio ao Comitê Editorial: Patrícia Balthazar Garcia

Diagramação, Revisão de português e normalização: Edson Leonel de Oliveira

Revisão de inglês: Ananyr Porto Fajardo 